\title{
Contra el "afuera" y el "obstáculo- sustancialista". Una crítica a las lecturas esencialistas de Michel Foucault
}

\author{
Against the "outside" and the "obstacle-substancialist." A \\ critique of Michel Foucault's essentialists readings
}

Contra o "exterior" e o "obstáculo-substancialista". Uma crítica às leituras essencialistas de Michel Foucault

Prof. José Ignacio Scasserra*

\section{RESUMEN}

El siguiente artículo se propone poner de relieve el aspecto inmanente de las relaciones de poder en los trabajos foucaultianos, por medio de discutir con ciertas lecturas post-foucaultianas sobre la biopolítica que, en nuestra opinión, han caído en esencialismos a partir de postular un "afuera" incontaminado por la mano del poder. Para ello realizaremos una lectura de La voluntad de saber que ponga en valor la crítica a la "hipótesis represiva", contraponiéndola con el desarrollo de Imperio, de Hardt y Negri, deteniéndonos en los puntos en los que, consideramos, los autores apelan a un "afuera" a las relaciones de poder. Identificaremos esta operación teórica como "obstáculo-sustancialista", y buscaremos señalar sus límites y alcances. Finalmente, haremos un balance del recorrido, destacando autorxs contemporáneos que discutan actualmente la idea de "afuera".
Palabras clave: Foucault, poder, crítica, represión, Imperio

Argentino. Profesor de enseñanza superior y media en filosofía. Investigador (CONICET / UBA, Argentina) en el Instituto de Investigaciones de Estudios de Género (FFyL, UBA, Argentina). Doctorando en filosofía (FFyL, UBA, Argentina). Miembro de la cátedra abierta "Félix Guattari", del colectivo "Mariposas Mirabal" (Educación sexual integral) y CEIPH (Cooperativa de educadores e investigadores populares histórica). Contacto: j_scasserra@hotmail.com.

ORCID: https://orcid.org/0000-0003-4864-748X 


\section{SUMMARY}

The following article aims to highlight the immanent aspect of power relations in Foucauldian works. To this end, we will discuss with specific post-Foucauldian readings on bio politics. In our opinion, readings that have fallen into certain essentialisms by postulating an "exterior" unsoiled by the hand of power. To this end, we will carry out a reading of The Will to Know that values the critique of the "repressive hypothesis." Showing to what extent Foucault seeks to close the way to any ontological thought that imagines "backgrounds" that have been left uncontaminated by the hand of power. With this in mind, we will make a reading of Empire by Hardt and Negri, as we consider them to be strong exponents of Foucault's readings that have incurred an "outside" to power relations. We will identify this theoretical operation as "obstacle-substantialist" and seek to point out its limits and scope. Finally, we will balance the route, highlighting contemporary authors who currently discuss the idea of "outside."

\section{RESUMO}

O seguinte artigo propõe como objetivo destacar o aspecto imanente das relações de poder nas obras de Foucault. Para isso, discutiremos com certas leituras pós-foucaultianas sobre a biopolítica que, em nossa opinião, caíram em certos essencialismos ao postular um "exterior" incontaminado pela mão do poder. Para isso, faremos uma leitura de A Vontade de Saber que valorize a crítica da "hipótese repressiva", mostrando até que ponto Foucault procura fechar o caminho para qualquer pensamento ontológico que imagine "recintos" que permaneceram incontaminados pela mão do poder. Com isto em mente, faremos uma leitura de Império, de Hardt e Negri, por considerá-los fortes expoentes das leituras de Foucault que incorreram em um "exterior" às relações de poder. Identificaremos esta operação teórica como "obstáculo-substancialistas" e procuraremos determinar seus limites e escopo. Finalmente, faremos um balanço do trajeto, destacando autores contemporâneos que atualmente discutem a ideia de "exterior".
Keywords:

Foucault, power, criticism, repression, Empire

Palavras-chave: Foucault, poder, crítica, repressão, Império 
“Los puntos de resistencia están presentes en todas partes dentro de la red de poder. Respecto del poder no existe, pues, un lugar del Gran Rechazo - alma de la revuelta, foco de todas las rebeliones, ley pura del revolucionario-. Pero hay varias resistencias que constituyen excepciones, casos especiales: posibles, necesarias, improbables, espontáneas, salvajes, solitarias, concertadas, rastreras, violentas, irreconciliables, rápidas para la transacción, interesadas o sacrificiales; por definición, no pueden existir sino en el campo estratégico de las relaciones de poder".

MiCHEL FoUCAULT, Historia de la sexualidad I: La voluntad de saber, 2011, p. 92.

\section{Introducción general: La mano invisible del poder}

Ya no hay un afuera al que aspirar: quizás esta sea la consecuencia más fértil de las reflexiones hechas por Michel Foucault sobre la biopolítica. Las promesas de una utopía por llegar, o de un mundo a construir, exento totalmente de las dinámicas que día a día juzgamos insuficientes o violentas, pierden efectividad en la reflexión post-foucaultianas. No hay, pues, una "verdadera" revuelta que nos salve del furor histórico que nos ha hecho ser lo que somos. Al contrario, se pone de manifiesto que la mano invisible del poder se encuentra ya operando, desde siempre y a nuestras espaldas, construyendo nuestros deseos, nuestros discursos y nuestras acciones.

Pero esto no quiere decir que no existan contrapesos, resistencias o instancias de crítica: simplemente se señala que éstas deben ser buscadas en la inmanencia de las relaciones de poder, y no por fuera de las mismas. No hay aquí "derrotismo", sino un punto de partida para el pensamiento: el de dar por supuesto que ya hemos sido capturadxs y constituidxs ${ }^{1}$ por las lógicas que pretendemos criticar. Por todo ello, recoger el guante de los trabajos sobre las mecánicas del poder en Michel Foucault no debe entenderse como un gesto de resignación, sino como un intento más de quien pretende comprender la complejidad que tenemos ante nosotrxs.

Ahora bien, estos elementos que señalamos en los trabajos foucaultianos sobre el poder no siempre son leídos de esta forma. Han existido, especialmente en su línea receptora italiana, numerosas lecturas (Laza-

1 N. de la Ed.: se ha decidido no alterar el lenguaje inclusivo presente en el texto original, respetando la escritura propia del autor. 
ratto 2007; Agamben 2006; Hardt y Negri 2002; Federici 2016)² que, contra todo el espíritu nietzscheano de Foucault, incurren en ciertas lecturas sustancialistas de su propuesta, suponiendo un fondo incorruptible del sujeto de la biopolítica. Desde nuestra perspectiva, este tipo de interpretaciones acaban por decantar en la postulación de un "afuera" de las relaciones de poder, identificado con ese fondo sustancial supuesto.

Nuestra hipótesis de lectura es que estos trabajos post-foucaultianos incurren en estas conclusiones por perder de vista la importancia que la crítica a la "hipótesis represiva" posee a lo largo de La voluntad de saber. Si se olvida que, para Foucault, el poder es productivo y que sus funciones represivas son meramente secundarias (Deleuze 2013 67), permanecemos en la búsqueda de una "verdadera" naturaleza o fondo revolucionario que puja permanentemente por salir. Seguimos, de este modo, atrapadxs por un esquema represivista que concibe al poder como aquello que inhibe las bondadosas energías de la revolución.

Por todo lo dicho, en el presente trabajo nos proponemos contribuir a los estudios post-foucaultianos por medio de discutir con este tipo de lecturas. Tomaremos como exponente de las mismas el libro Imperio de Michael Hardt y Antonio Negri. Siguiendo nuestra hipótesis, sostendremos que, por incurrir en lo que llamaremos "obstáculosustancialista", los autores terminan construyendo una visión negativa del poder, al cual se opone un deseo sustancial antepuesto a la constitución histórica del mismo, olvidando de esta forma la crítica a la hipótesis represiva desarrollada por Foucault en La voluntad de saber. No

2 Escribe Lazarato que "Foucault está interesado en determinar lo que en la vida le resiste y, al resistírsele, crea formas de subjetivación y formas de vida que escapan a los biopoderes. Definir las condiciones de un nuevo 'proceso de creación política, confiscado desde el siglo XIX por las grandes instituciones políticas y los grandes partidos políticos', me parece ser el hilo rojo que atraviesa toda la reflexión de Foucault. En efecto, la introducción de la 'vida en la historia' es positivamente interpretada por Foucault como una posibilidad de concebir una nueva ontología que parte del cuerpo y de sus potencias para pensar el 'sujeto político como un sujeto ético"' (Lazarato 2007 83). Creemos que este gesto se repite en la distinción que recupera Agamben entre zoe y bios para realizar una nueva lectura biopolítica (Agamben 2006). Los casos en que Hardt y Negri realizan este tipo de lecturas son numerosos, pero no los adelantaremos por ser sobre los que nos ocuparemos a lo largo de este artículo. Por último, creemos que Silvia Federici apela a este tipo de razonamientos, a pesar de haber discutido con ellos (Federici 2014 182), cuando postula al cuerpo de la mujer como el foco de resistencia al capital (Federici 2016 30). Saliendo de la línea italiana, el gesto se repite en Testo Yonki de Paul B. Preciado, al postular la Potentia Gaudendi como "la potencia (actual o virtual) de excitación (total) de un cuerpo" (Preciado 2014 41). 
proponemos esta discusión con el espíritu de generar lecturas "más auténticas" que se ciñan mejor a la fuente foucaultiana. Lo hacemos por la convicción filosófica, ética y política de que una lectura sustancialista de Foucault no es deseable hoy en día para la producción de pensamiento crítico. Si queremos insertar nuestra labor intelectual en su actualidad y rastrear contrapesos y resistencias posibles, estimamos que el mejor camino es buscar cómo la mano invisible del poder ya nos ha influido, y no persiguiendo nuestro ser "auténtico" e incorrupto.

En vistas de este objetivo, en primer lugar, revisaremos los lineamientos generales de La voluntad de saber, definiendo qué es la "hipótesis represiva" y destacando su carácter local y parcial dentro del mecanismo más amplio que la contiene, esto es, el dispositivo de sexualidad. Allí observaremos cómo aquélla es deudora de la concepción "jurídicodiscursiva" del poder, mientras que el dispositivo de sexualidad solo es observable si adoptamos un modelo "estratégico productivo" del mismo. En segundo lugar, desarrollaremos las tres preguntas instaladas por Foucault a la "hipótesis represiva", es decir, la histórica, la históricoteórica, y la histórico-política. En estos dos apartados realizaremos un estudio de registros eclécticos, en el sentido de que comenzaremos anclando nuestra pregunta en la sexualidad, pero veremos cómo, a partir de ella, se dará un proceso de abstracción que terminará por interrogar por el funcionamiento general del poder. A lo largo de todo este desarrollo haremos un esfuerzo por destacar los aspectos des-sustancialistas de la propuesta foucaultiana, los cuáles formularemos al final por medio de proponer una "cuarta" pregunta a la "hipótesis represiva". Con todo esto en el tintero, y como contrapunto, abordaremos Imperio de Hardt y Negri, para señalar los puntos en que, creemos, realizan su lectura sustancialista de Foucault. Por último, recuperaremos el recorrido realizado poniendo de relieve otras lecturas post-foucaultianas, que se ciñen más a nuestro modo de leer al autor, en vistas de producir una conclusión en la que ensamblaremos lo trabajado.

\section{Lo que el soberano no ve}

\subsection{El proyecto genealógico}

Comenzar a desarrollar el libro La voluntad de saber nos insta, en primer lugar, a encuadrarlo en el marco de los trabajos que Foucault ve- 
nía realizando en esos años. Si se respeta el esquema tripartito que el propio autor describió en el prólogo de $E l$ uso de los placeres (Foucault 2011b 12) y en la primera clase de El gobierno de sí y de los otros (Foucault 2010 20-21) podemos afirmar que los trabajos foucaultianos se dividen en a) una serie de investigaciones arqueológicas que priorizan el estudio de las formaciones de saber, b) los estudios genealógicos que abordan los dispositivos de poder, y c) un período ético que estudia las formas de subjetivación ${ }^{3}$. Estos pasajes consisten en diferencias de acentos, y no en grandes rupturas dentro del autor: al pasar, por ejemplo, de los estudios arqueológicos a los genealógicos, se adopta el estudio de prácticas no discursivas sin renunciar al de las prácticas discursivas (Castro 2011 171).

La voluntad de saber se inscribe en el segundo periodo. La tarea de la genealogía será la de rastrear "la singularidad de los sucesos, fuera de toda finalidad monótona (...) captar su retorno, pero en absoluto trazar una curva lenta de una evolución" (Foucault 1992 7). Podemos apreciar el esfuerzo colocado en destacar el funcionamiento específico de la particularidad, sin suponer grandes desarrollos meta-históricos que se desplieguen teleológicamente hacia un fin establecido. Por eso, en este primer apartado partiremos de la particularidad histórica de la sexualidad, pero previniéndonos de que, eventualmente, haremos un proceso de abstracción que nos permita hacernos una pregunta por el funcionamiento del poder en general a partir de la modernidad.

\subsection{Caballo de Troya}

El capítulo que da comienzo a La voluntad de saber titulado "Nosotros, los victorianos" funciona como un caballo de Troya que, en su primera lectura, probablemente nos haga quedar en ridículo. Foucault comien-

$3 \quad$ Nos atenemos a la nominación que utiliza Foucault en El uso de los placeres más que en El gobierno de sí y los otros, si bien conceptualmente da el mismo desarrollo, utiliza expresiones diferentes. Apelamos a este esquema por resultarnos útil para ordenar y periodizar los trabajos foucaultianos, como hacen numerosos comentadores (Castro 2014; Gros 2007). Ahora bien, no queremos dejar de mencionar que consideramos que la propia división presenta sus problemas, ya que, con Alvarez Yaguez (2015 11), consideramos que es posible subsumir todos los periodos a un gesto ético y a una pregunta por los modos de subjetivación que se manifiestan con más fuerza en los últimos trabajos. Bajo esta perspectiva, el concepto de "crítica" que hemos abordado en otras ocasiones (Scasserra 2018b 2019), y que es el centro de nuestras investigaciones, aparece como un posible hilo conductor que nos permita ordenar y abordar el proyecto foucaultiano. 
za a describir lo que llama el "régimen victoriano" y el modo en que, dentro de éste, la sexualidad se ha visto confiscada por el puritanismo moderno, que le habría impuesto su triple decreto de "prohibición, inexistencia y mutismo" (Foucault 2011a 11). Acompañamos con entusiasmo la descripción de cómo el orden burgués reprimió consecuentemente la sexualidad en vistas de catalizar las energías hacia el trabajo productivo, e ingresamos en este orden de cosas sin chistar. $Y$ justo cuando el autor parece estar por convencernos, troca el orden de sus preguntas en un gesto casi burlón: ya no importa interrogarnos por nuestra represión, sino que nos pregunta: “¿Por qué decimos con tanta pasión, tanto rencor contra nuestro pasado más próximo, contra nuestro presente y contra nosotros mismos, que estamos reprimidos?" (Foucault 2011a 14). Toma así forma ante nosotros la llamada "hipótesis represiva", contra la que el autor va a arremeter durante todo el libro. Aquello que nos había parecido una idea muy acertada mientras el autor la describía, aparece ahora como objeto de nuestras sospechas.

En este primer gesto, el autor nos hace abandonar lo que hacía pocas páginas se nos aparecía como obvio. Ya no se tratará de una denuncia a lo que el orden burgués haya hecho o no sobre nuestra sexualidad $^{4}$, o al menos no en términos tan directos. Se tratará de un gesto más astuto y sutil: el de desconfiar de aquello que nos compele a decir que el sexo ha sido reprimido, por descubrir que no es más que un aspecto local y parcial de un mecanismo más antiguo y complejo. Al respecto, Foucault nos advierte que todos los elementos negativos que aglutina la "hipótesis represiva" "sólo son piezas que tienen un papel local y táctico que desempeñar en una puesta en discurso, en una técnica de poder, en una voluntad de saber que están lejos de reducirse a dichos elementos" (Foucault 2011a 18).

Podemos ver, entonces, cómo la "hipótesis represiva" nace en el marco de un dispositivo más amplio, que ella no percibe ni comprende. Este mecanismo será designado por el autor como "dispositivo de sexualidad", y consistirá en el gesto simple pero efectivo que aglutina una multiplicidad heterogénea en torno al imperativo de "hablar de

4 En Defender la sociedad, el autor afirmará que "del fenómeno general de la dominación de la clase burguesa puede deducirse cualquier cosa” (Foucault 2014 40), mostrando una vez más su desconfianza ante este tipo de explicaciones y posicionándose respecto de los debates de su época. 
sexo" (Miller 1996 68), buscando alojar en el discurso la verdad última de sus misterios y dándose simultáneamente un correlato por medio de construir un campo de prácticas específico sobre el que predicarse. El trabajo de Foucault consiste en rastrear cómo, desde finales del siglo XVI, "la puesta en discurso del sexo, lejos de sufrir un proceso de restricción, ha estado por el contrario sometida a un mecanismo de incitación creciente" (Foucault 2011a 18). La efectividad de este mecanismo se prueba por el caballo de Troya que nos ha regalado el autor: he allí el motivo por el cual, como lectores primerizos, aceptamos velozmente las acusaciones hacia la moral burguesa.

Pero es necesario profundizar aún más. En este gesto de subsumir la "hipótesis represiva" a un mecanismo más amplio que la contiene, se encuentra, desde nuestra perspectiva, el corazón teórico del proyecto de La voluntad de saber: es decir, la crítica a un modelo específico de comprender el poder (jurídico-discursivo) y el reemplazo del mismo por un nuevo modo de entenderlo (estratégico-productivo). Este pasaje es lo que abordaremos a continuación.

\subsection{Hipótesis Reich, hipótesis Nietzsche}

El pasaje de un modelo "jurídico-discursivo" del poder, que prioriza la represión, a un modelo "estratégico-productivo", que da cuenta de los contrapesos y choques que el poder realiza en un campo de inmanencia, es esquematizado velozmente por Foucault en el curso Defender la sociedad como la contraposición de dos modelos: la "hipótesis Reich" ${ }^{5}$ y la "hipótesis Nietzsche". Sobre la primera quedaría asociada la idea de "represión" de nuestros "verdaderos" afectos y motivos, mientras que en la segunda lo que se vislumbra es un campo complejo de intereses, contrapesos y alianzas.

La "hipótesis Reich" comprende, pues, al poder "como un derecho que uno posee como un bien y que, por consiguiente, puede transferir o enajenar, de una manera total o parcial, mediante un acto jurídico o

$5 \quad$ Lleva este nombre por el pensador freudo-marxista Wilhelm Reich. En sus desarrollos podemos encontrar una manifestación clara de un "afuera" propuesto en la energía revolucionaria del orgasmo que preexistiría a la mano invisible del poder y que, al ser liberado, generaría la deseada revolución. 
un acto fundador de derecho" (Foucault 201426 ) 6 . El poder se reduce de esta manera a un bien transferible que, en su renuncia, generaría la institución de toda soberanía, deviniendo de esta manera el sujeto en súbdito ${ }^{7}$. El edificio jurídico que queda de este modo construido para el rey (Foucault 2014 36) le sirve de instrumento y justificación, y lo coloca en el centro para otorgarle la capacidad de inhibir cualquier intento de revuelta, por asumir que toda potencia o poder ya le ha sido concedida.

Por ser un bien enajenado, el poder solo está en manos del soberano para limitar cuerpos y deseos que intenten recuperar dicha propiedad. De esta forma, su repertorio de herramientas se encuentra limitado a una relación negativa respecto de su objeto de ejercicio: "El poder nada puede, sobre el sexo y los placeres, salvo decirles que no" (Foucault 2011a 80). Su campo de acción consiste en montar un terreno de lo prohibido y de lo permitido, amenazando con suprimir a quien sea que cruce la frontera. Esto implica asumir un comportamiento uniforme y unitario del mismo: el poder solo sabe inhibir "aquello" que se asume que quedó fuera de la enajenación.

La contrapropuesta de Foucault es la del modelo estratégico-productivo del poder, que parte de "pensar el sexo sin la ley y, a la vez, el poder sin el rey" (Foucault 2011a 88). El poder será ahora comprendido como una multiplicidad de relaciones de fuerza "inmanentes y propias del campo en el que se ejercen, y que son constitutivas de su organización" (Foucault 2011a 89). Allí lo que prioriza no es la negatividad, sino un juego de apoyos, desniveles, contradicciones y devenires que dan lugar a una situación estratégica compleja en una sociedad determina-

6 Sobre este punto, y para desarrollar otros, el autor retoma la figura de Thomas Hobbes. Creemos que su concepción de poder como medio para la obtención de un fin lo lleva a una formulación de pacto social que resuena mucho con la figura soberana que Foucault se encuentra criticando: "Autorizo y abandono el derecho a gobernarme a mí mismo a este hombre, o asamblea de hombres, con la condición de que tú abandones tu derecho a ello y autorices todas tus acciones de manera semejante" (Hobbes 2011 166). En el pacto hobbesiano se ve la renuncia de una potencia o capacidad que todo ser humano "poseería" en un orden previo de cosas, y que entregaría al soberano como si fuera un bien intercambiable.

$7 \quad$ Intervenimos la traducción de Fondo de Cultura Económica del curso Defender la sociedad, por entender que es un tanto oscura para la lengua española. Allí Horacio Pons decide afirmar que la institución de la soberanía es el pasaje del "sujeto al sujeto" para preservar el juego de palabras que Foucault realiza en el francés "sujet au sujet", siendo que, en su lengua, sújeto y subdito coinciden en la palabra "sujet". 
da. Lo que resalta aquí es el conflicto (de allí que se destaque la figura de Nietzsche) y no la opresión unidireccional de un individuo o grupo sobre otros. Por todo ello, el poder conformará situaciones específicas, será productor e incitador de discursos y formas de vida, anudará subjetividades virtuales y posibles; será más lo que afirmará que lo que inhibirá. La posibilidad de contestar, responder, criticar o agenciar será entonces siempre dentro de esta red compleja de contrapesos, y jamás por fuera de la misma.

Sobre este punto, resta decir que Foucault jamás niega la existencia propia de la represión. En Defender la sociedad Foucault va a anunciar que "estas dos hipótesis no son inconciliables; al contrario: parecen incluso encadenarse con bastante verosimilitud: la represión, después de todo, ¿no es la consecuencia política de la guerra (...)?" (Foucault 201429 ). El error no se encuentra en afirmar que el poder reprima, sino en considerar que este es el principal y único mecanismo que posee; realizado el pasaje teórico hacia el modelo "estratégico-productivo" del poder, el mecanismo represivo no desaparece, sino que adquiere una dimensión secundaria (Deleuze 2013 67).

Por todo ello, el objetivo de La voluntad de saber es demostrar entonces que, a partir de la modernidad, nos encontramos inmersos en una trama que no abunda en mecanismos para silenciar el sexo, sino que hunde sus raíces en la organización discursiva acerca de éste, que buscaría organizarlo en especies, perversiones, personajes, cuerpos y modos que alojan un lugar de verdad sobre lo que somos; contar cómo hemos sido reprimidos no es más que un capítulo de esta historia. Poder traducir esa verdad, recogerla en palabras, colocarla en nuestra elocuencia y, de ese modo, dar cuenta de nosotrxs mismxs ${ }^{8}$, es el pun-

8 Al respecto, no queremos dejar de llamar la atención sobre cómo las políticas de identidad, especialmente sobre derechos de la llamada "comunidad LGBT", en los cuales Argentina ha sido pionera, pueden ser pensadas como formas terminales del "dispositivo de sexualidad". Esto lo señalamos no para desconocer las luchas y reivindicaciones históricas de las disidencias sexuales (de las cuales hemos participado y nos sabemos parte), pero sí para entender el arco argumental puramente moderno en el que nos inscribimos, y prevenirnos sobre la producción de verdad permanente a la cual somos arrojados a diario en vistas de restituir derechos. Una perspectiva que no tenga en cuenta la crítica a la "hipótesis represiva" corre el riesgo de comprender todo el movimiento de ampliación de derechos como algo que se "opone" al poder, que está por fuera de sus intereses. Nosotrxs, a partir de lo trabajado aquí, preferimos comprenderlo como un contrapeso y una disputa dentro del marco del "dispositivo de sexualidad", entendiendo que 
to terminal del dispositivo de sexualidad que, hasta el día de hoy, no parece haber menguado.

\subsection{De la negación a la administración}

Recuperando los desarrollos de este apartado, podemos dar cuenta cómo la extensión del "dispositivo de sexualidad" y la inserción de la "hipótesis represiva" en su interior solo es observable si adscribimos a la "hipótesis Nietzsche", es decir, si comprendemos al poder en su dimensión estratégico-productiva. Por el contrario, si nos mantenemos en la perspectiva del poder soberano, solo podemos rastrear las dimensiones negativas del ejercicio del poder, por lo que el argumento extenso del "dispositivo de sexualidad" se desdibuja: el soberano no puede ver que el accionar represivo es un elemento más de una historia más amplia y profunda que lo contiene.

Respecto de nuestro modo general de lidiar con las tramas de poder en las cuales nos involucramos, cabe señalar que, si cambiamos la concepción "jurídico-discursiva" del poder por una "estratégicoproductiva", nuestro foco se dirige no tanto a la pregunta por cómo somos negados, sino por cómo hemos sido administrados. El problema no está en qué cosas nos son vedadas, sino en cómo se nos está haciendo vivir. Allí, nuestra participación en la red inmanente de la que buscamos diferenciarnos adquiere una dimensión activa. Por ello es que, si adquirimos la perspectiva "estratégico-productiva", podemos ver los modos en que somos incitados a colocarnos en determinadas posturas, participar de determinados discursos, adquirir determinadas costumbres. Una perspectiva desinformada sobre este tipo de problemáticas no puede sino insistir con la "hipótesis Reich", postulando un "afuera" de las relaciones de poder, a partir de imaginar aquello que

fue éste incluso quien posibilitó gran parte del éxito de nuestras conquistas. Al respecto, ser ecléctico sobre los registros del pensamiento filosófico y de la lucha jurídica en el marco del Estado de Derecho, pudiendo dar discusiones en este escenario sin renunciar a la capacidad reflexiva, puede resultar muy fértil. Sobre este tema, creemos que Judith Butler se ha expedido magistralmente en el epílogo de El género en disputa, destacando su carácter problemático: "La deconstrucción de la identidad no es la deconstrucción de la política; más bien instaura como política los términos mismos con los que se estructura la identidad. Este tipo de crítica cuestiona el marco fundacionista en que se ha organizado el feminismo como una política de la identidad. La paradoja interna de este fundacionismo es que determina y obliga a los mismos sujetos que espera representar y liberar" (Butler 2016 288). 
subsiste al acto de enajenación del poder por parte de los súbditos. A partir de este concepto, las líneas programáticas solo pueden imaginar proyectos emancipatorios a partir de liberar "aquello" que se encontraba reprimido por "debajo" de la mano del poder, y jamás dando cuenta del rol activo que las subjetividades encuentran en las situaciones estratégicas en las cuales se ven a diario involucradas.

\section{Las tres (o cuatro) preguntas foucaultianas}

\subsection{La sexualidad como circunstancia}

En el prólogo de El uso de los placeres, Foucault se propone revisar y explicitar lo que había intentado realizar en el proyecto de su Historia de la sexualidad. Allí señala que lo que le inquietaba era poder dar cuenta de cómo los sujetos habían sido llevados a indagar sobre sí mismos y sobre los demás. En vistas de realizar ese objetivo, el comportamiento sexual aparece como una circunstancia, ocasionalmente privilegiada, pero "no de dominio exclusivo" (Foucault 2011b 11).

Esta dimensión es señalada por Foucault especialmente en las "artes de la existencia" greco-latinas. Ahora bien, recuperamos la expresión y la dislocamos para abordar el "dispositivo de sexualidad" que hemos desarrollado previamente. Si bien es cierto que los análisis de Foucault en esta ocasión son sobre la sexualidad y los placeres, también es cierto que ponen en juego una concepción particular de cómo entender el poder y, creemos, de qué entender por "sí mismo", o incluso por "sujeto". A continuación, nos proponemos señalar ese registro ecléctico, ya presente en nuestro apartado anterior, entre la circunstancialidad de la sexualidad y la generalidad del sujeto y el poder. Lo desarrollaremos a lo largo de las tres preguntas que Foucault instala a la sexualidad en La voluntad de saber. Al final de nuestro apartado, asimismo, buscaremos sostener que a esas tres preguntas podemos agregar una cuarta, latente, de corte ontológico, que nos permitirá hacer nuestro contrapunto posterior con Hardt y Negri.

\subsection{La pregunta histórica}

La primera pregunta nos insta a dirigirnos a la evidencia histórica disponible sobre la represión que la modernidad habría montado sobre la sexualidad: “¿Es la represión del sexo una evidencia histórica?”, se in- 
terroga Foucault, buscando de este modo hacer hablar al archivo para montar una nueva luz sobre la problemática. A esto, Foucault va a responder que la misma es propia de una concepción "jurídico-discursiva" de la ley, que ya desarrollamos previamente, y que adoptarla como el elemento principal en nuestras investigaciones nos compromete, respecto del poder, a "pensarlo a partir de una forma histórica muy particular de nuestras sociedades: la monarquía jurídica" (Foucault 2011a 86). El papel de la particularidad que destacamos en el apartado anterior adopta entonces una función fundamental: la de prevenirnos de exportar acríticamente concepciones propias de un momento histórico que dista de ser el nuestro.

En el curso Defender la sociedad Foucault ampliará sobre esta cuestión, abandonando la circunstancia de la sexualidad y abordando el problema de la evidencia histórica desde el funcionamiento general del poder, lo cual nos fuerza a adoptar el registro ecléctico que ya anticipamos. El modelo "jurídico-discursivo" sobre el poder soberano, al que responde la "hipótesis represiva", data en efecto de la Edad Media y del resurgimiento del Derecho romano, constituyéndose en torno a la monarquía y el monarca. Para el autor, esta concepción del poder cumple con determinadas funciones:

1) Se refiere a los mecanismos de poder efectivos de la monarquía feudal. En este punto queremos llamar la atención acerca de lo ya dicho: no se trata de negar la represión verificable en la historia, sino de decir que fue el elemento fundamental del poder en un modelo específico que ya no es el actual.

2) Sirvió de instrumento y justificación para la constitución de las grandes monarquías administrativas. Este segundo elemento muestra el momento de "bisagra" en el que se opera el pasaje del modelo jurídico y soberano del poder al que el autor llamará "estratégico-productivo". La convivencia o simultaneidad (Lorey 2017 96) de los dos modelos en este periodo, refuerza lo que el autor ya había advertido: no se trata de negar la represión, pero sí de poner en duda que sea el elemento fundamental del ejercicio del poder. Aquí, por ejemplo, vemos cómo convive con el incipiente modelo administrativo del Estado que se asocia a la concepción "estratégico-productiva". 
3) Fue funcional tanto para expandir el poder real como para limitarlo a lo largo de los siglos XVI y XVII, ya que servía tanto para defender las monarquías administrativas como para fundamentar la democracia parlamentaria.

Por ello, concluye Foucault, mientras duró el feudalismo el modelo jurídico-discursivo abarcaba el tipo de poder vigente. Eventualmente se produjo la aparición de una nueva mecánica de poder, con procedimientos particulares que gradualmente irán volviéndose incompatibles con el poder monárquico. De modo que, si ensayamos una respuesta a la primera pregunta foucaultiana, observamos que contamos con evidencia histórica de una concepción del poder que priorizaba su dimensión represiva, pero que ésta responde a las monarquías feudales, y que fue perdiendo su centro gradualmente con el advenimiento de la modernidad y de las relaciones capitalistas de producción, hasta configurarse como lugar subsidiario o secundario.

\subsection{La pregunta histórico-teórica}

La segunda pregunta es la histórico-teórica: “¿es la mecánica del poder del orden de la represión?". Aquí creemos que se pone de manifiesto con mayor claridad el registro ecléctico que venimos proponiendo: pareciera que Foucault abandona la circunstancia de la sexualidad por completo, incluso dentro de la Historia de la sexualidad, para preguntar por la "mecánica del poder".

Sobre este punto Foucault señala que, si solo consideramos la noción negativa del poder, no comprendemos su modo relacional y nos arriesgamos a perder su complejidad. En efecto, el poder, lejos de funcionar de forma negativa, inhibiendo cualquier manifestación que le sea contraria, entabla con nosotrxs una relación más compleja: ya no buscará obturar al placer, sino que entre ambos polos se perseguirán, excitarán y reactivarán. Esta concepción será deudora de los principios metodológicos con los cuales el autor habría abordado la noción misma de poder que repusimos en el apartado anterior. En alguna medida, todo el pasaje del modelo "jurídico-discursivo" al "estratégico-productivo" del poder puede operar como una respuesta a esta pregunta.

Sin embargo, podemos agregar ahora que, en virtud de comprender el poder como un campo de inmanencia productivo y estratégico, los polos excluyentes e inmóviles entre dominantes y dominados, 
opresores y oprimidos, violentos y violentados, caen por considerar cada situación como un orden de cosas específico en el que los sujetos adquieren una dimensión activa sobre la situación de la que son hechos parte. Aceptado esto, ya no queda mucho lugar para rastrear índices de verdad subjetivos y externos a las lógicas del poder: el deseo, la sexualidad, el placer o la búsqueda misma de emancipación, se encontrarán, desde el comienzo, dentro de una compleja trama de relaciones de poder, en la que los "dominados" ejercen un rol más activo del que tradicionalmente se les habría asignado ${ }^{9}$. Llamamos momentáneamente la atención acerca del modo en que esta concepción de poder compromete la noción de "deseo", extrayéndola de un lugar impoluto para colocarla inmediatamente dentro de un escenario relacional, ya que será importante más tarde para operar nuestro contrapunto con Hardt y Negri.

\section{4. La pregunta histórico-política}

Esta tercera pregunta indaga sobre los efectos de la "hipótesis represiva": su enunciación reiterada, ¿cierra el paso a la operación del poder, o hace sistema con él? Por todo lo dicho, podemos dar cuenta velozmente de la incapacidad contestataria de la "hipótesis represiva", ya que ésta no puede ver ni dar cuenta cómo participa del mecanismo más amplio que la contiene y la ha hecho posible. Por ello, señala Foucault que "la posibilidad misma de su éxito estaba vinculada al hecho de que se desplegaba siempre dentro del dispositivo de sexualidad, y no fuera de él o contra él" (Foucault 2011a 126). De allí que se afirme que, donde autores como Wilhelm Reich creían ver la posibilidad de la emancipación, descuidaban el hecho de que estaban bajo la sujeción del dispositivo mismo de la sexualidad occidental.

Esta tercera pregunta encierra para nosotros dos sentidos que queremos destacar: en primer lugar, nuevamente nos hace incurrir en el registro ecléctico que venimos destacando. Así como en nuestra sexua-

$9 \quad$ Hoy esta concepción ha sido puesta en cuestión, especialmente por pensadoras de líneas feministas que, a partir de ciertas particularidades históricas, proponen incluir dentro de la perspectiva "estratégico-productiva" del poder una dimensión represiva que le resulte constitutiva. Destacamos de estos valiosos aportes Calibán y la bruja, de Silvia Federici, y Disputas sobre el sujeto, de Isabell Lorey. Abordamos las críticas de Federici a Foucault en un artículo publicado en la revista Crítica y Resistencias titulado "Brujas omitidas" (Scasserra 2018a). 
lidad, en líneas generales, también sucede que permanecer bajo el esquema represivista suele hacer sistema con las lógicas del poder, ya que no nos permite dar cuenta de cómo hemos sido ya configurados y nos encontramos inmersos en las relaciones que decimos criticar.

En segundo lugar, esta tercera pregunta fundamenta nuestra decisión hermenéutica que enunciamos en nuestra introducción general. En efecto, no se trata de afirmar que somos mejores lectores de Foucault, sino que proponemos una divergencia con las lecturas sustancialistas, para evitar postular un fondo en el que resida la fórmula para la emancipación, ya que creemos que, más que cerrarle el paso al poder, estas perspectivas suelen hacer sistema con él. Contra ese tipo de espejos de colores, preferimos optar intelectual, ética y políticamente por la paciente labor del archivista, que busca rastrear cómo es que el poder se encuentra ya habitándonos.

\subsection{La pegunta ontológica}

Seis años después de la publicación de La voluntad de saber, interrogado por la idea de "liberación", Foucault respondía:

Tendríamos que ser en lo que se refiere a esto un poco más prudentes. Siempre he desconfiado un tanto del tema general de la liberación, en la medida en que, si no lo tratamos con algunas precauciones y en el interior de determinados límites, se corre el riesgo de recurrir a la idea de que existe una naturaleza o un fondo humano que se ha visto enmascarado, alienado o aprisionado en y por mecanismos de represión como consecuencia de un determinado número de procesos históricos, económicos y sociales. Si se acepta esta hipótesis, bastaría con hacer saltar estos cerrojos represivos para que el hombre se reconciliase consigo mismo, para que se reencontrase con su naturaleza o retomase el contacto con su origen y restaurase una relación plena y positiva consigo mismo. Me parece que este es un planteamiento que no puede ser admitido así, sin más, sin ser previamente sometido a examen (Foucault 1984 100).

Creemos que esta respuesta viene a retomar aquélla incomodidad manifestada en La voluntad de saber. En efecto, el pasaje del modelo "jurídico-discursivo" al "estratégico-productivo" era una reflexión en torno al estatus del poder, que proponía des-sustancializarlo para comprenderlo como una relación. Ahora bien, aquí el autor muestra 
que era, asimismo, una reflexión respecto del sujeto. Si permanecemos en el esquema represivista, nos vemos obligados a suponer una "naturaleza" o "fondo humano" que operaría como faro, tierra prometida a la que llegar.

En definitiva, la "muerte del hombre" anunciada en Las palabras y las cosas, que rechazaba la idea de cualquier constitución antropológica a priori, encuentra aquí un nuevo rostro. Por eso nos atrevemos a decir que, como Kant habría sintetizado sus tres preguntas en la interrogación antropológica (“¿qué es el hombre?”), es posible agregar una cuarta pregunta similar a las blandidas por Foucault previamente. “¿Qué es el hombre?” en el sentido de “¿existe una sustancia ontológica previa a las relaciones de poder y a las configuraciones históricas, llámese ésta deseo, potencia, trabajo, o vida?". La respuesta es, desde Foucault, por supuesto negativa.

En el mismo artículo que citamos para caracterizar la genealogía, Foucault muestra cómo la misma se sostiene sobre una burla y un abandono de la idea misma de "origen". Realizando un estudio del abordaje que Nietzsche realiza del término "Ursprung" (Nietzsche 2011 9), extrae como balance general que lo que allí hay es un rechazo por "recoger allí la esencia exacta de la cosa, su más pura posibilidad, su identidad cuidadosamente replegada sobre sí misma, su forma móvil y anterior a todo aquello que es externo, accidental y sucesivo" (Foucault 1991 10). Creemos que este rechazo por el origen, comprendiéndolo en términos sustanciales, es el espíritu nietzscheano que Foucault buscó actualizar en sus trabajos. Allí cobra valor la contingencia, la particularidad y el azar que las genealogías foucaultianas ponen en valor y donde se vuelve imperativo recuperar sus devenires para no rastrear algún tipo de origen impoluto de nuestras subjetividades y nuestros modos de ofrecer resistencia.

\section{El imperio del "obstáculo-sustancialista"}

\subsection{El "manifiesto comunista" del siglo XXI}

En el año 2000 el mundo intelectual, militante y político recibió con avidez un tomo que hasta el día de hoy no puede pasarnos desapercibido. Imperio, de Michael Hardt y Toni Negri, se propuso hacer un nuevo diagnóstico de la situación geopolítica mundial, trazando su historiza- 
ción y rastreando sus posibles grietas y fisuras. A partir de una actualización del pensamiento marxista que se entrelaza con un lenguaje deleuziano-guattariano (encontramos expresiones como "cartografía", "línea de fuga", "territorialización") y con los desarrollos biopolíticos de Michel Foucault, los autores buscan barajar y dar de nuevo, para estar a la altura del capital globalizado y del "nuevo orden mundial" aparecido y consolidado a partir de la caída del muro de Berlín.

El impacto fue tal que Žižek afirmó que nos encontrábamos ante el "manifiesto comunista del siglo XXI" (Žižek 2001). En efecto, la importancia de Imperio no puede ser negada. Gran parte de sus diagnósticos pueden encontrarse como telón de fondo de múltiples textos teórico-militantes ${ }^{10}$ que hoy en día leemos con avidez. Asimismo, su efectividad en tanto acontecimiento político e intelectual es rescatable desde el punto de vista de haber implicado una revitalización del pensamiento marxista en conjugación con la experiencia autonomista: si, como afirma Mariano Pacheco, el siglo XXI comenzó en 1994 con la revuelta zapatista (Pacheco 2019 20), la afirmación de Žižek adquiere mayor sustento.

Ahora bien, esta amplia recepción les valió a los autores, asimismo, numerosas críticas. No faltó quienes señalaran las debilidades de sus diagnósticos histórico-políticos (Boron 2002; Bellamy Foster 2001). Metodológicamente, se ha señalado la falta de economía política en sus argumentaciones (Rush 2003 286), y políticamente una apelación constante a un subjetivismo voluntarista, gesto atribuible al autonomismo italiano (Rush 2003 294; Acha 2003 13) ${ }^{11}$. Por nuestra parte realizaremos una lectura que no se detenga tanto en esta multiplicidad de aspectos, sino en lo que creemos fundamento de numerosos puntos ciegos del libro: la sustancialización de la multitud como sujeto revolucionario. Como Descartes propone respecto de sus opiniones en las Meditaciones Metafísicas (Descartes 2004 119), optamos por no discutir los análisis de los autores uno por uno, sino que nos dirigimos

10 Pienso, por ejemplo, en Realismo Capitalista de Mark Fisher (2016), el “Manifiesto por una política aceleracionista" de Willams y Srnicek, o la propuesta Xenofeminista del colectivo Laboria Cuboniks (Avanessian y Reis 2017)

11 Debo este estado de la cuestión al artículo "La teoría posmoderna del imperio (Hardt y Negri) y sus críticos", de Alan Rush. Recomiendo su lectura para una buena síntesis de la recepción crítica de Imperio. 
a su fundamento, ya no para derribarlo, sino para trazar sus límites y alcances.

\subsection{Del imperialismo soberano al Imperio transnacional}

"El imperio se está materializando ante nuestros propios ojos" (Hardt y Negri 2002 11). Con este orden de cosas nos encontramos al comenzar la lectura del libro. Los autores bien saben que esta situación no se dio de la noche a la mañana, por lo tanto, nos proponen realizar un valioso recorrido histórico-filosófico para trazar la genealogía de nuestra situación actual. Para dar con sus causas, los autores se remontan a los albores de la modernidad.

Para Hardt y Negri la modernidad es el resultado de una crisis (Id. 78), de un conflicto no resuelto entre dos fuerzas antagónicas. La primera, propia de un proceso revolucionario que descubrió la plenitud "del plano de la inmanencia" (Id. 76) y que, gracias a su potencial constructivo y creativo, logró cortar con las instancias trascendentes del orden previo: es decir, el fin de las fundamentaciones políticas en trasmundos e instancias supraterrenales. La segunda, una contrarrevolución que procuró dominar y expropiar la fuerza de los movimientos y la dinámica emergente. Este mito originario que blanden los autores es comprendido como "el orden contra el deseo" (Id. 77); las fuerzas del orden habrían intentado restaurar la trascendencia, mientras que las fuerzas del deseo, defender la inmanencia.

Esta batalla fue ganada por la primera fuerza, la fuerza del orden, asociada a la Ilustración ${ }^{12}$. De esta manera construyeron la soberanía moderna, reinstalando la trascendencia ${ }^{13}$. A partir de este momento, el deseo emancipatorio de comunidad, propio de la multitud, debió

12 Atribuimos las divergencias con nuestra lectura de Foucault en parte a esta lectura de la Ilustración, la cual dista mucho de ser la propuesta por Foucault en sus textos de 1983 y 1984, “¿Qué es la ilustración?” (Foucault 2002).

13 No queremos dejar de mencionar que nos resulta sumamente complejo atribuir "trascendencia" a la filosofía política moderna. Los autores toman el Leviatán de Thomas Hobbes como referente de la reinstauración de un orden trascendente (Hardt y Negri 2002 287), haciendo una lectura que desconoce que todo el problema de la filosofía política moderna es producir una justificación del Estado que ya no recaiga en principios trascendentes, bajo el convencimiento de que el cuerpo político es un artificio. En el caso de Hobbes, lo que opera de fundamento de la construcción política es el pacto como expresión de la voluntad individual, y no un principio trascendente o teocrático, que es justamente todo lo que el Leviatán se propone combatir. 
entrar en latencia y convivir con la "captura" de los Estados-nación. Este es el fundamento del orden moderno colonialista, expansionista, imperialista y, por supuesto, capitalista. Lo que está juego es la tensión y ampliación de límites territoriales en búsqueda de nuevos mercados y recursos.

Este orden moderno se ve roto en el pasaje a lo que los autores insisten en llamar "posmodernidad" ${ }^{14}$, caracterizada por poner en crisis la idea de "soberanía". Este segundo pasaje es el que describe el paso del imperialismo al Imperio. En contraste con el imperialismo, el Imperio no establece ningún centro de poder y no se sustenta en fronteras o barreras fijas. Es un aparato descentrado y desterriorializador de dominio que progresivamente incorpora la totalidad del terreno global dentro de sus fronteras abiertas y en permanente expansión. Ahora bien, esto no quiere decir que la soberanía haya caído. Los autores lo dicen en varias ocasiones: ésta sencillamente ha cambiado de forma, ya que ahora está "compuesta por una serie de organismos nacionales y supranacionales unidos por una única lógica de dominio" (Id. 11).

Como Marx y Engels hicieron en el Manifiesto con la burguesía (Marx 2014 70), los autores hacen lo mismo con el Imperio: se toman unas breves páginas para realizar un "elogio" al Imperio, por su capacidad para cambiar la base material y productiva del globo (Hardt y Negri 2002 52). Por eso, cualquier movimiento emancipatorio debe estar a la altura del capital trasnacional, abandonando las fronteras rígidas de la soberanía. Un movimiento contra el imperio no debe hacer resurgir a los Estados-nación como afrontas al capital internacional: de nada serviría apelar a una estructura previa, ya superada.

Allí ingresa la recepción foucaultiana. Se hace coincidir el pasaje del imperialismo al Imperio con el pasaje del esquema "jurídicodiscursivo" del poder al "estratégico-productivo" que desarrollamos en nuestros apartados previos. Esto se explica por medio de igualar

14 Aunque reconocen la insuficiencia del término ( $I d .212$ ), son incapaces de producir otra nominación y lo utilizan a lo largo de todo el libro. Por nuestra parte, como Foucault, desconfiamos sumamente de la expresión "posmodernidad", y creemos que en todo caso nos encontramos en una "hipermodernidad" en la que el subjetivismo moderno se ha hiperbolizado, y la soberanía de los Estados sigue cumpliendo un papel central en el desarrollo del Capital, lejos de haber sido superada. 
la soberanía a la trascendencia y el capital, a la inmanencia ${ }^{15}$. El poder soberano habría quedado en la instancia previa, y lo que ahora tendríamos ante nosotros sería la red múltiple y descentrada descrita por Foucault en La voluntad de saber. Es importante aquí destacar que el pasaje para Foucault es previo: la inauguración de la modernidad requiere ya de un esquema estratégico-productivo, y la presencia del mismo en lo que Hardt y Negri llaman "posmodernidad" no hace sino reforzar la idea de que nos encontramos ante una modernidad hiperbolizada, cuyos mecanismos se han reforzado y en absoluto superado. En otras palabras, Hardt y Negri hacen ingresar tardíamente el esquema estratégico-productivo en su sistema, postulando aquí una ruptura (pasaje del imperialismo al Imperio) donde Foucault siempre vio continuidad.

Sea como fuera, en el nuevo estado de cosas que nos encontramos "el objeto de dominio es la vida social en su totalidad; por consiguiente, el Imperio presenta la forma paradigmática del biopoder" (Hardt y Negri 2002 14). Se rescatan los desarrollos de Foucault en los cuales el poder es entendido como una red de contrapesos siempre inmanente. Los autores saben muy bien que el Imperio, y el capital, no puede dejar nada por fuera de sí: dicen frecuentemente que no hay un afuera del poder. Ahora bien, lo que el poder invade son "cerebros" y "cuerpos" con el propósito de "llevarlos hacia un estado autónomo de alienación, de enajenación del sentido de la vida y del deseo de creatividad" (Id. 36).

Esta contraposición entre alienación y creatividad, que tan poco foucaultiana resuena, se debe en términos teóricos a que, para los autores, por debajo de la lectura de Foucault, siempre está operando la ontología deleuziana. En efecto, los autores van a criticar a Foucault el no poder dejar ir cierta "epistemología estructuralista" que consiste en "la reinvención de un análisis funcionalista" que "sacrifica la dinámica

15 Esta homologación posee, creemos, una potencial línea de investigación. En efecto, el poder "estratégico-productivo" como forma abstracta de lo social posee numerosos ecos con la definición de "capital" aportada por Marx, especialmente a partir de las lecturas de Moishe Postone. Si en la modernidad capitalista del siglo XXI las relaciones de poder se han universalizado como formas de mediación social, produciendo la totalidad subjetiva y objetiva de lo real (Exposto, Rodríguez Varela 2019 225), creemos fundamental incorporar lecturas foucaultianas a la llamada "crítica del valor" que se viene desarrollando en los últimos años. 
del sistema, la temporalidad creativa de sus movimientos y la sustancia ontológica de la reproducción cultural y social" (Id. 39). El problema es que ellos autores no pueden atribuir a Foucault una ontología, y por ello apelan a Deleuze y Guattari, quienes, en la perspectiva de Hardt y Negri, logran abandonar el marco epistemológico estructuralista y son propiamente posestructuralistas, dirigiendo "nuestra atención a la sustancia ontológica de la producción social” (Id. 40).

El problema allí será, como se intentará mostrar en el siguiente apartado, que la lectura que los autores harán de Deleuze y Guattari encontrará en su ontología aspectos propios de la metafísica de la sustancia occidental. Este es el punto de bisagra en el cual, creemos, los autores se traicionan a sí mismos, y dejan ingresar por la ventana aquello que habían expulsado por la puerta: el "afuera" del poder.

\subsection{El "obstáculo-sustancialista"}

Para Hardt y Negri, el poder no produce mundos virtuales y formas de vida posibles, como había señalado Foucault. El poder nos "aliena" y "enajena" del sentido de la vida y del deseo. A lo largo de todo el libro los autores van a proponer una ontología del deseo y la producción manifestada en la figura que evocan como solución de la historia: la multitud. Veremos a continuación cómo funciona.

"La formación del imperio es una respuesta al internacionalismo proletario." (Id. 58). Lo verdaderamente productivo es, pues, la multitud. El imperio no es más que una respuesta al movimiento afirmativo que ésta posee, y que había quedado latente desde los comienzos de la modernidad. Lo prioritario no es la forma social en su abstracción, ni en su modo relacional, sino el deseo de la multitud, que lo antecede.

La multitud se postula pues como pura generación, "aparato colectivo de deseo" (Id. 337), y a ella se le opone, desde los comienzos de la modernidad, la "corrupción", la cual es "contraria al deseo" por no ser "un motor ontológico, sino simplemente la falta de un fundamento ontológico en las prácticas biopolíticas del ser" (Id. 338). Esto lleva a Hardt y Negri a oponer la multitud al Imperio como se oponen la ciudad de los hombres con la ciudad de Dios en San Agustín (Id. 341). La primera será juzgada como buena por ser ontológicamente productiva y deseante, portadora del "trabajo vivo", y la otra como mala por ser 
parasitaria y, como un vampiro, drenar las energías productivas de la multitud, produciendo "trabajo muerto"16.

Esta oposición entre el deseo de la multitud y la captura del Imperio permite dar cuenta del mecanismo principal de Hardt y Negri: reúnen el diagnóstico biopolítico de Foucault, pero lo colocan sobre una lectura sustancialista de la ontología del deseo de Deleuze y Guattari. Si bien los autores de El anti-edipo no dejan de afirmar que su ontología está históricamente determinada, y no preexiste a las influencias del poder sobre la misma (sino nunca podrían sostener un "plano de inmanencia"), es difícil encontrar este gesto en los desarrollos de Hardt y Negri, ya que comprenden que los deseos de la multitud son siempre buenos, revolucionarios y productivos por naturaleza, cosa que ni Deleuze ni Guattari aceptarían sin más ${ }^{17}$. Por todo ello, en esta propuesta sobre el deseo productivo de la multitud no encontramos configuraciones históricas, sino una sustancia por fuera de las determinaciones circunstanciales. Más que una descripción de lo que es, una prescripción de lo que debería ser. Un deseo quizás más axiológico que ontológico.

Allí, entonces, los autores de Imperio terminan olvidando la dimensión histórica y positiva de la biopolítica, y pasan a comprender al poder de forma meramente negativa:

La relación que impone el gobierno imperial sobre la virtualidad de la multitud es simplemente una relación estática de opresión. Las intervenciones del gobierno imperial son en esencia negativas, se las despliega mediante procedimientos que procuran ordenar coercitivamente las acciones y los acontecimientos que amenazan con derivar en desorden (Hardt y Negri 2002 314).

De este modo, Hardt y Negri parecen haber leído la Historia de la sexualidad omitiendo el punto de partida de la misma: la crítica a la

16 Dentro de la tradición autonomista italiana, Silvia Federici realiza, en "Sobre el trabajo afectivo", duras críticas a esta distinción entre trabajo vivo y trabajo muerto blandida por Hardt y Negri, compilado en Revolución en punto cero (Federici 2013 181-203).

17 "Cuando sujetos, individuos o grupos actúan claramente contra sus intereses de clase, cuando se adhieren a los intereses e ideales de una clase que su propia situación objetiva debería determinarles a combatir, no basta con decir: han sido engañados, las masas han sido engañadas. No es un problema ideológico, de desconocimiento y de ilusión, es un problema de deseo, y el deseo forma parte de la infraestructura. Las catexis preconscientes se hacen o deberían hacerse según los intereses de clases opuestas" (Deleuze y Guattari 2014 113). 
"hipótesis represiva". Esta omisión les hace postular una multitud, si bien heterogénea y múltiple, coherentemente revolucionaria, ontológicamente deseante e históricamente productiva. En contraposición, habría un Imperio naturalmente opresor, antiontológico e históricamente corruptor del trabajo de su víctima. Proponemos llamar "obstáculo-sustancialista" a este mito simplista, transhistórico, y dualista sobre el funcionamiento del poder, el cual decanta finalmente en una axiología política y voluntarista más que en una ontología filosófica. Creemos que, como telón de fondo, se encuentra operando una lectura sustancialista de las máquinas deseantes de Deleuze y Guattari, olvidando de este modo que, para los autores franceses, el deseo es ante todo una configuración histórica. Esta falta de historización los lleva a convertir a la multitud en una "caja negra" (Acha 2003 20), que parece incluir todo lo que los autores desean promover.

\subsection{El "afuera" del poder}

Como dijimos, en muchas oportunidades los autores insisten en que no hay un "afuera" del poder, y que se debe "actuar en el Imperio y contra él" (Hardt y Negri 2002 15). Parecen haber comprendido muy bien la red inmanente que describió Foucault, y su rechazo a la trascendencia parece ser radical. Pero en un discurso oscilante, que muchas veces raspa la contradicción, los autores terminan postulando inconfesadamente un "afuera" del poder, ubicándolo en el deseo de la multitud.

Como ya adelantamos, consideramos que esta operación se debe a no haber tenido en cuenta la importancia de la crítica a la "hipótesis represiva", en especial en la valencia que adquiere en la "cuarta pregunta" que propusimos sobre la misma. La búsqueda por escapar de las lógicas de la sustancia, sostenida por Foucault, se ha desdibujado y, por ende, tanto el sujeto de la revolución como la concepción misma de poder se han resustancializado. Si el deseo de la multitud es ontológicamente impoluto y revolucionario, se convierte inmediatamente en el lugar que aloja todas las respuestas para nuestras ansias de emancipación. De modo que las enunciaciones de que no hay un "afuera" del poder, punto del cual partieron al describir el Imperio, pierden fuerza por prometerle al lector, una y otra vez, un "afuera" que resuena a la tierra prometida del esquema judeo-cristiano. 
Por último, queremos destacar que estas reflexiones no funcionan meramente en un plano filosófico o especulativo. La postulación o no de una ontología, a la hora de hacer filosofía y política, muchas veces pasa por un plano de decisión ${ }^{18} \mathrm{y}$, en definitiva, debemos juzgarla por sus efectos. En este caso, creemos que la multitud como sujeto revolucionario y deseante termina, en Imperio, teniendo consecuencias negativas para nuestras retóricas políticas. Afirmamos esto porque, en primera instancia, no permite asumir el problema de cómo la multitud pueda desear o aplaudir el fascismo, o su propia dominación (problema que el marco teórico del cual se sirve Hardt y Negri sí asumió ${ }^{19}$ ). Asimismo, lleva a los autores a afirmar que "la movilidad y el nomadismo masivo de los trabajadores siempre expresa una negativa y la búsqueda de liberación: la resistencia contra las horribles condiciones de explotación y la búsqueda de la libertad y de nuevas condiciones de vida" (Id. 191). Por apelar al obstáculo-sustancialista, y atribuir al nomadismo condiciones emancipadoras ("máquina de guerra", como los autores de Mil Mesetas propusieron) (Deleuze y Guattari 1988 359431), desconocen la situación de precariedad a la que miles de migrantes son empujadxs. Donde hay condiciones formales de dominación, que llevan a producir mano de obra barata, ven una búsqueda individual o grupal de "libertad"; donde a lo sumo quizás haya deseo de ascenso social, los autores encuentran la búsqueda "de nuevas condiciones de vida".

Por ello, aprovechamos de repetir que no se trata de imputar la lectura foucaultiana por considerarla una "mala lectura", que se aleja de la fidelidad del texto fuente. Realizamos las críticas precedentes por considerarlas un obstáculo para pensar nuestras prácticas intelectuales y militantes, ya que postulan un lugar sagrado en el que todas las respuestas habitan, e inhiben cualquier pregunta sobre nuestra complicidad y adhesión a las relaciones de poder que decimos criticar.

18 Escribe Omar Acha que "El énfasis político-militante de Imperio sugiere otra aproximación, que se funda en una ontología o metafísica vitalista incompatible con el deconstruccionismo radical. La deconstrucción halla un límite cuando se encuentra con la potencia ontológica de la multitud. He aquí la decisión metafísica fundamental" (Acha 2003 14).

19 A pesar de citar la pregunta de Wilhelm Reich de "¿por qué las masas desearon al fascismo?" (retomada, asimismo, por Deleuze y Guattari), los autores parecen desconocer este problema a lo largo del libro, mostrándose optimistas con los deseos emancipatorios de la multitud. 


\section{Conclusión general: cómplices y críticxs}

En un capítulo realmente magistral de El arte queer del fracaso, Jack Halberstam analiza los múltiples vínculos entre nazismo y homosexualidad. Narra historias sobre pelotones de hombres gays durante el tercer Reich, y rastrea cómo esa configuración decanta hasta nuestros días en estéticas eróticas leather, que podemos encontrar, por ejemplo, en los trabajos de Tom de Finlandia. Para hacer este análisis, el autor recupera la crítica a la "hipótesis represiva" de Michel Foucault, con el fin de producir un "archivo contradictorio", evitando así narrativas que sitúen "al valiente queer como un heroico luchador por la libertad en un mundo de puritanos" (Halberstam 2018 160)

Este gesto es el que quisimos rescatar a lo largo de nuestro estudio, por supuesto no instanciado en la particularidad queer, sino en la cultura de izquierda en general. Si regresamos a La voluntad de saber y pusimos en valor la crítica a la "hipótesis represiva", lo hicimos con el fin de extraer las consecuencias antisustancialistas que ésta encierra, tanto respecto del poder (comprendiéndolo entonces como una relación) como con el sujeto político (comprendiéndolo ya intervenido, configurado y constituido por "la mano invisible" del poder").

De este modo, la acción política, tanto reproductora como trasgresora con el statu quo, pasa a ser un elemento inmanente a una red de contrapesos, y en absoluto la manifestación de un deseo ontológico que subyace por "fuera" de las relaciones de poder, preexistiendo a la incidencia del poder. Con todo esto en el tintero, la lectura de Imperio de Hardt y Negri y de múltiples otrxs autonomistas, especialmente en su línea italiana, se llena de problemas por no poder construir un programa político y teórico que prescinda de este tipo de postulaciones. Como pudimos ver en nuestro análisis, los autores terminan contradiciéndose, incorporando el "afuera" del poder en el deseo de la multitud, figura que habían rechazado inicialmente.

Ahora bien, nos gustaría agregar que otra preocupación que se suma a la fábula idealizada de este sujeto revolucionario, es el rol del intelectual de izquierda en él. Stengers y Pignard, en La brujería capitalista, reflexionan al respecto:

Si la movilización de las masas se plantea como primordial, todo fracaso podrá ser explicado por el hecho de que las masas no se 
movilizaron, o que no logramos movilizar a las masas. Y precisamente está allí hoy en día el problema. Porque los militantes anticapitalistas se ven entonces llevados a convertirse en pedagogos y misioneros, a aclarar sus verdaderos intereses ante movimientos en adelante reacios, que tienen lecturas divergentes de las situaciones, definiciones diferentes de las posturas y las estrategias (2017 55).

Citamos este trabajo por considerarlo una propuesta posfoucaultiana que, en contraposición a Hardt y Negri, propone no buscar un "afuera" del poder y se logra mantener en esa línea. Allí el objetivo es "sobrevivir al capitalismo (oponerse a él en él)" (Id. 23). Lxs autorxs se cuidan mucho de no postular ningún tipo de ontología deseante, ningún sujeto de la revolución, ningún acto meramente negativo del poder. Por el contrario, la pregunta está colocada en cómo nuestro deseo se encuentra configurado por la mano invisible del poder; por cómo somos rehenes de los discursos que describieron a la "clase obrera como una gran fuerza independiente de cualquier medio, definida por una vocación universal desde su inicio". Contra esto, se busca no apelar a ninguna gran teoría, sino a "la preocupación de encontrar las palabras para no aplastar el presente" (Id. 152).

Desmontar la sustancia revolucionaria en pos de conectarnos con el funcionamiento del poder en su particularidad tiene un efecto inmediato y, desde nuestra perspectiva, deseable: la de enseñarnos a desconfiar de nosotrxs mismxs. El antisustancialismo foucaultiano decanta, inmediatamente, en una "ontología crítica de nosotros mismos", como puso de relieve el autor en sus últimos años. Ya advertimos que nuestra propuesta de no buscar un afuera no pretende derivar en derrotismo: el movimiento demora, pero se da desde un "nosotros" hacia un "nosotros", y no desde un "yo" hacia un "ellos". Si superamos el chantaje de estar "por fuera" o "por dentro" del poder, podemos dirigirnos hacia la pregunta de hasta qué punto hemos sido históricamente determinadxs por él. Rastrear los límites y alcances de esa influencia nos permite, pues, desprender "de la contingencia que nos hizo ser lo que somos la posibilidad de ya no ser, hacer o pensar lo que somos, hacemos o pensamos" (Foucault 2002 102).

Allí una sutileza final: remarquemos que las posibilidades de ser de otra forma, de construir otro mundo, es decir, de concretar algún proyecto emancipatorio, se desprenden del propio barro histórico 
que nos ha hecho ser lo que somos, de aquélla mano invisible del poder que tanto hemos señalado. No podemos sino, pues, ser cómplices y críticxs de aquello que nos ha constituido. Allí anida la posibilidad de cambio histórico. Las posibilidades de una "vida otra", como quería Foucault, residen en la astucia con la que podemos mover los resortes de nuestra actualidad en favor de nuestros objetivos tácticos, y no en la apelación a un deseo revolucionario que parece preexistir en nosotrxs.

\section{Bibliografía general}

Acha, Omar. "La filosofía de la historia en Imperio de Michael Hardt y Anotnio Negri", en Epistemología e Historia de la Ciencia 9 (2003).

Agamben, Giorgio. Homo Sacer. Valencia: Pre-textos, 2006.

Álvarez Yagüez, Jorge. "Introducción: una ética del pensamiento". La ética del pensamiento. Michel Foucault. Madrid: Biblioteca Nueva, 2015.

Avanessian y Reis. Aceleracionismo. Estrategias para una transición hacia el postcapitalismo. Buenos Aires: Caja Negra, 2017.

Boron, Atilio. Imperio \& Imperialismo. Una lectura crítica de Michael Hardt y Antonio Negri. Buenos Aires: CLACSO, 2002.

Bellamy Foster, John. "Imperialism and 'Empire", Monthly Review 53/7 (2001).

Butler, Judith. El género en disputa. Buenos Aires: Paidós, 2016.

Castro, Edgardo. Diccionario Foucault. Buenos Aires: Siglo XXI, 2011. Introducción a Foucault. Buenos Aires: Siglo XXI, 2014

Deleuze, Gilles. En medio de Spinoza. Buenos Aires: Cactus, 2008. . Curso sobre Foucault I. El saber. Buenos Aires: Cactus, 2013.

Deleuze, Gilles y Guattari, Félix. Mil Mesetas. Capitalismo y Esquizofrenia. Valencia: Pre-textos, 1988. , El anti-edipo. Buenos Aires: Paidós, 2014.

Descartes, René. Meditaciones Metafísicas. Buenos Aires: Terramar Ediciones, 2004.

Exposto, Emiliano y Rodriguez Varela, Gabriel. "Para otro diálogo entre marxismo y psicoanálisis freudiano: una relectura categorial de León Rozitchner", Teoría y Crítica de la Psicología 12 (2019): 223-244. 
Federici, Silvia. Calibán y la bruja. Mujeres, cuerpo y acumulación originaria. Buenos Aires: Tinta Limón, 2016.

Federici, Silvia. Revolución en punto cero. Buenos Aires: Traficantes de sueños, 2013.

Fisher, Mark. Realismo capitalista, ¿no hay alternativa? Buenos Aires: Ed. Caja negra, 2016.

Foucault, Michel. "La ética del cuidado de uno mismo como practica de libertad", Concordia 6 (1984): 99-116.

"Nietzsche, la genealogía, la historia". Microfísica del poder, Madrid: ed. de la Piqueta, 1992.

¿Qué es la ilustración? Córdoba: Alción, 2002.

El gobierno de sí y de los otros. Buenos Aires: Fondo de Cultura Económica, 2010.

Historia de la sexualidad I: La voluntad de saber. Buenos Aires: Siglo XXI, 2011a.

. Historia de la sexualidad II: El uso de los placeres. Buenos Aires: Siglo XXI, $2011 \mathrm{~b}$.

Defender la sociedad. Buenos Aires: Fondo de Cultura Económica, 2014.

Gros, Fréderic. Michel Foucault. Buenos Aires: Paidós, 2007.

Halberstam, Jack. El arte queer del fracaso. Córdoba: Ven te veo, 2018.

Hardt, Michael y Negri, Antonio. Imperio. Buenos Aires: Paidós, 2002.

Hobbes, Thomas. Leviatán, o la materia, forma y poder de una república eclesiástica y civil. Buenos Aires: Losada, 2011.

Lazaratto, Maurizio. "Del biopoder a la biopolítica”, Brumaria 7: Arte, Máquinas, trabajo inmaterial (2007).

Lorey, Isabell. Disputas sobre el sujeto. Adrogué: La Cebra, 2017.

Marx, Karl. Antología. Buenos Aires: Siglo XXI, 2014.

Miller, Jaques-Alain. "Foucault y el psicoanálisis". Michel Foucault, filósofo. Barcelona: Gedisa, 1996.

Nietzsche, Frederich. La genealogía de la moral. Buenos Aires: Libertador, 2011.

Pacheco, Mariano. Desde abajo y a la izquierda. Movimientos sociales, autonomía y militancias populares. Buenos Aires: Las Cuarenta y El Río sin orillas, 2019.

Petras, James. "Imperio con imperialismo". 2001 octubre 29. 
Preciado, Paul B. Testo Yonki. Sexo, drogas, y biopolítica. Buenos Aires: Paidós, 2014.

Rush, Alan. "La teoría posmoderna del imperio (Hardt y Negri) y sus críticos". Filosofía política contemporánea, Controversias sobre civilización, imperio y ciudadanía, Atilio A. Borón. CLACSO.

Scasserra, José. "Brujas omitidas. Un estudio en torno a las críticas de Silvia Federici a Michel Foucault", Crítica y Resistencias 8, Córdoba (2018a).

. "Ruptura y continuidad", Ágora filosófica 18, Pernambuco (2018b).

. "La crítica como ética del cuidado de sí", Cuestiones de filosofía, Colombia (2019).

Stengers, Isabelle y Pignarre, Philippe. La brujería Capitalista. Buenos Aires: Hekht Libros, 2017.

Žižek, Slavoj. Rethinking Marxism 13/3-4 (2001). 